\title{
An Audit on Compliance of Surgical Time- Out after a Decade of Implementation at an Academic Tertiary Care Hospital
}

\author{
Talal A. Al-Khatib ${ }^{1}$, MBBS, FRCSC, Ahmad A. Mirza², MBBS, Manar A. Malakah'1, MBBS, \\ Afnan E. Jiffri ${ }^{1}$, MBBS, Lujain K. Abdalwassie ${ }^{1}$, MBBS, and Dina M. Hijazi ${ }^{1}$ \\ ${ }^{1}$ Department of Otolaryngology, Head and Neck Surgery, ${ }^{2}$ Faculty of Medicine, \\ King Abdulaziz University, Jeddah, Saudi Arabia \\ ${ }^{2}$ From Department of Otolaryngology, Head and Neck Surgery, Faculty of Medicine-Rabigh \\ King Abdulaziz University, Rabigh, Saudi Arabia
}

\section{Correspondence}

Dr. Talal A. Al-Khatib

Department of Otolaryngology,

Head and Neck Surgery, Faculty of Medicine

King Abdulaziz University

P.O. Box 80215, Jeddah, Saudi Arabia

talkhatib@kau.edu.sa

\section{Submission: $\quad 09$ Feb. 2019}

Accepted: $\quad 05$ Apr. 2019

\section{Citation}

Al-Khatib TA, Mirza AA, Malakah MA, Jiffri AE, Abdalwassie LK, Hijazi DM. An audit on compliance of surgical time-out after a decade of implementation at an academic tertiary care Hospital. JKAU Med Sci 2019; 26 (1): 19-27. DOI: 10.4197/Med. 26-1.4

Copyright: (๑) The Author(s), YEAR. Publisher. The Journal of King Abdualziz University - Medical Sciences is an Official Publication of "King Abdulaziz University". It is an open-access article distributed under the terms of the Creative Commons Attribution Non-Commercial License, which permit unrestricted non-commercial use, distribution, and reproduction in any medium, provided the original work is properly cited.

\begin{abstract}
A surgical safety checklist is essential to ensure patient safety. The purpose of this study was to evaluate the implementation of surgical time-out at an academic medical center in Saudi Arabia, and to reveal potential factors that may influence the compliance of time-out. A cross-sectional study observing elective surgeries was performed at King Abdulaziz University Hospital. Sixteen operating theaters were screened, corresponding to 15 different specialties being examined. Overall, one hundred and sixteen elective procedures were observed. The time-out checklist was employed by staff in $45.7 \%$ of cases and was fully completed in $26.7 \%$. Factors influencing the time-out adherence included overall staff presence and the involvement of the primary surgeon during the time-out phase $(p<0.001)$. Absence of some staff members was significantly associated with a higher rate of time-out noncompliance ( $\mathrm{OR}=0.04 ; 95 \% ; \mathrm{Cl}=0.01,0.21 ; \mathrm{p}<0.001$ ). There was no significant association between time-out and the time of the day that the surgery was performed $(p=0.83)$, nor the number of surgeries performed in the day. Overall, time-out compliance was suboptimal in this study. Time-out was conducted at a similar rate throughout the day, regardless of the surgical load and the length of the pre-incision period.
\end{abstract}

\section{Keywords}

Surgical time-out; Patient safety; Academic hospital

\section{Introduction}

\footnotetext{
Curgical service is a major and fundamental component of the healthcare system. Of more than 234 million major surgeries performed annually, adverse events occur in 3 to $17 \%$. Of these, lifelong disability or consequent death occur in about $12 \%$ to
}

$19 \%^{[1-3]}$. Not only are surgical complications a major cause of morbidity and mortality, they also result in financial burden ${ }^{[4]}$. In fact, at least half of these complications are preventable and could have been preoperatively predicted by surgical team members ${ }^{[2]}$. Of those incidents, wrong-side/wrong-site, wrong- 
procedure, and wrong-patient are devastating surgical events, more common than what healthcare providers perceive $^{[5]}$.

Surgical time-out is an essential tool to ensure adequate patient safety and to minimize errors ${ }^{[6]}$. As a preventing measure, the "Universal Protocol for Preventing Wrong Site, Wrong Procedure, Wrong Person Surgery" was introduced and adopted in 2003 by the Joint Commission on Accreditation of Healthcare Organizations. Subsequently, the World Health Organization (WHO) launched a checklist in 2008 for worldwide use, called the "Safe Surgery Checklist" ${ }^{\prime \prime[]}$. The use of this checklist in the operating room has been associated with a remarkable reduction in postoperative complication and mortality rate ${ }^{[8]}$.

In the operating theater, there are three consecutive phases of the surgical safety checklist. The first phase of the checklist is "sign-in," which occurs before the induction of anesthesia. The phase after induction of anesthesia but before surgical incision is called "time-out", and "sign-out" occurs when the wound is closed, before releasing the patient from the operating theater. Ideally, each phase should be recognized and performed appropriately by the operating team to ensuring that all checklist items are completed before proceeding to the next phase ${ }^{[9]}$. Each item of the safety checklist requires verbal confirmation by members of the surgical team to ensure the safe administration of anesthesia and antibiotic prophylaxis, to verify equipment availability, and to meet various surgical requirements.

In the time-out phase, all team members' names and roles should be identified. Then, the team is expected to briefly stop all actions immediately before the initial skin incision. The elements of timeout must be verbally verified, including the correct patient, operation, and operating site, and subjective case reviews should be heard from the surgeon, the anesthetist, and the nurse. The surgeon reviews anticipated blood loss and identifies any specific concerns from a surgical perspective. The anesthetist reviews any potential complications related to the anesthesia, such as complications of medication. Lastly, operating theater nurses confirm that all required medications have been given and that all necessary equipment has been checked and appropriately placed $^{[10] .}$.
Time-out is an important period in which the communication between healthcare providers is essential. Time-out can strengthen the communication among surgical team members, but poor communication between surgeons and other team members in the operation theater still exist ${ }^{[11,12]}$. Therefore, time-out should be continually evaluated and revised to sustain quality and safety of procedures.

Several observational studies were carried out to evaluate the compliance of time-out, particularly in developed countries. In these studies, a high compliance rate was observed, ranging from 80 to $100 \%{ }^{[13-15]}$. In the developing country of Ethiopia, however, a study revealed that time-out was not practiced in $35 \%$ of all surgical cases ${ }^{[11]}$.

There was a lack of previous research evaluating the compliance of time-out procedures in Saudi Arabia. Therefore, we aimed to evaluate the implementation and completion of time-out in a single center in Saudi Arabia, and to reveal potential factors that might influence the compliance of time-out.

\section{Methodology}

\section{Study Design}

A cross-sectional study was conducted following approval being obtained from the Ethics Committee at King Abdulaziz University Hospital-College of Medicine. The method used to assess time-out protocol adherence was direct observation, in that an observer was present during the period of time-out. Samples were collected using a convenience sampling technique. During observation, the purpose of the study was not made explicit to the members of the operating team.

\section{Study Setting}

King Abdulaziz University Hospital assigns 16 operating theaters to serve 15 different surgical specialties. In 2008 , the surgical time-out checklist was implemented as a safety measure for both elective and emergency procedures, and it involved assembling all operating theater team members (surgeons, anesthesiologists and nurses) before the procedure started. All elective surgeries being conducted at this center were included 
in our study, as they are regularly performed in assigned rooms on scheduled days and times. All surgical services were included in our evaluation (Appendix 1) except emergency and dental/maxillofacial services. A wide range of common procedures within each surgical specialty was observed.

\section{Data Collection and Management}

From August 2016 to May 2017, four medical students (L.A.; D.H.; M.M; A.J.) rotated operating theaters and directly observed procedures for compliance and completion of the surgical time-out checklist. They began their work before patients entered the operating theater and left when the surgical incision was performed. Observations were conducted in either half or full days. Daytime sessions were divided in three categories: the first surgery of the day; the surgeries between the first and last surgeries; and the last procedure of the day.

Data were collected by each student on data collection sheets using the variables implemented on the surgical time-out checklist. All collection forms contained anonymous data in order to ensure confidentiality, and all forms and identification sheets were placed in a safe, locked cabinet. One author (A.M.) transferred the data to a data excel sheet, and after verification, data were transferred directly to a statistical sheet. Permission was taken from the head nurse monitoring the operating theaters before we began the study, thus blindness was not guaranteed in this observationally based study. An attempt was made to avoid this potential bias, however, by arbitrarily keeping the list of operations that were attended.

\section{Time-out Process and Checklist}

The period after induction and before surgical incision is called surgical time-out. It involves all team members, and is a momentary pause, usually taken by the circulating nurses, to confirm that several essential safety checks were undertaken. All operating theater team members should introduce themselves and their role before surgery starts, and team leaders should elaborate their concerns in their respective area of specialty. The checklist also verifies the name of the patient, the name of the procedure, and the site/side of surgery. (Appendix 2)

\section{Power and Statistical Analysis}

Based on a previous report that identified the noncompliance rate of time-out (11\%) and with an estimated precision rate of \pm 0.06 or 6 percent and $95 \%$ confidence level, the calculated sample size was 105 . To avoid any reduction in sample size, we added $10 \%$ over the calculated number of samples ${ }^{[13]}$.

The compliance and completeness rate of timeout were calculated. Factors that were analyzed in respect to time-out compliance included procedure order (first, middle, and last), time interval prior to skin incision (the time from a patient being brought into the operating theater to the time of skin incision), presence of all staff, the involvement of primary surgeon, and the total number and specialty of surgical procedures in the day.

Statistical analysis was performed using the IBM SPSS Statistics for Windows, Version 21.0 (IBM Corp., Armonk, NY USA). Categorical variables were presented as frequency and percentage, continuous variables as mean \pm standard deviation (SD), and discrete variables as median ( $75^{\text {th }}$ percentile [P75]). Factors associated with time-out implementation were analyzed by comparing the characteristics of the procedures when time-out was implemented to those when it was not. Analysis included chi-square for categorical variables, an independent t-test for continuous variables (e.g., time between patient entering the operating theater and the initiation of surgical incision), and the MannWhitney $U$ test (nonparametric test) for discrete variables (e.g., total number of procedures per day, etc.). A $p$ value of less than 0.05 was considered to reject the null hypothesis.

\section{Results}

\section{Characteristics of Compliance to the Imple- mented Time-out Checklist}

A total of 116 elective procedures were screened for time-out compliance. Of those screened, the time-out checklist was observed in only $53(45.7 \%)$ cases. Of those, only $26.7 \%$ were fully completed.

Team members introduced themselves and their roles in only one (2\%) of 53 time-out reviewed cases. Of the 53 cases where the time-out was carried out, 


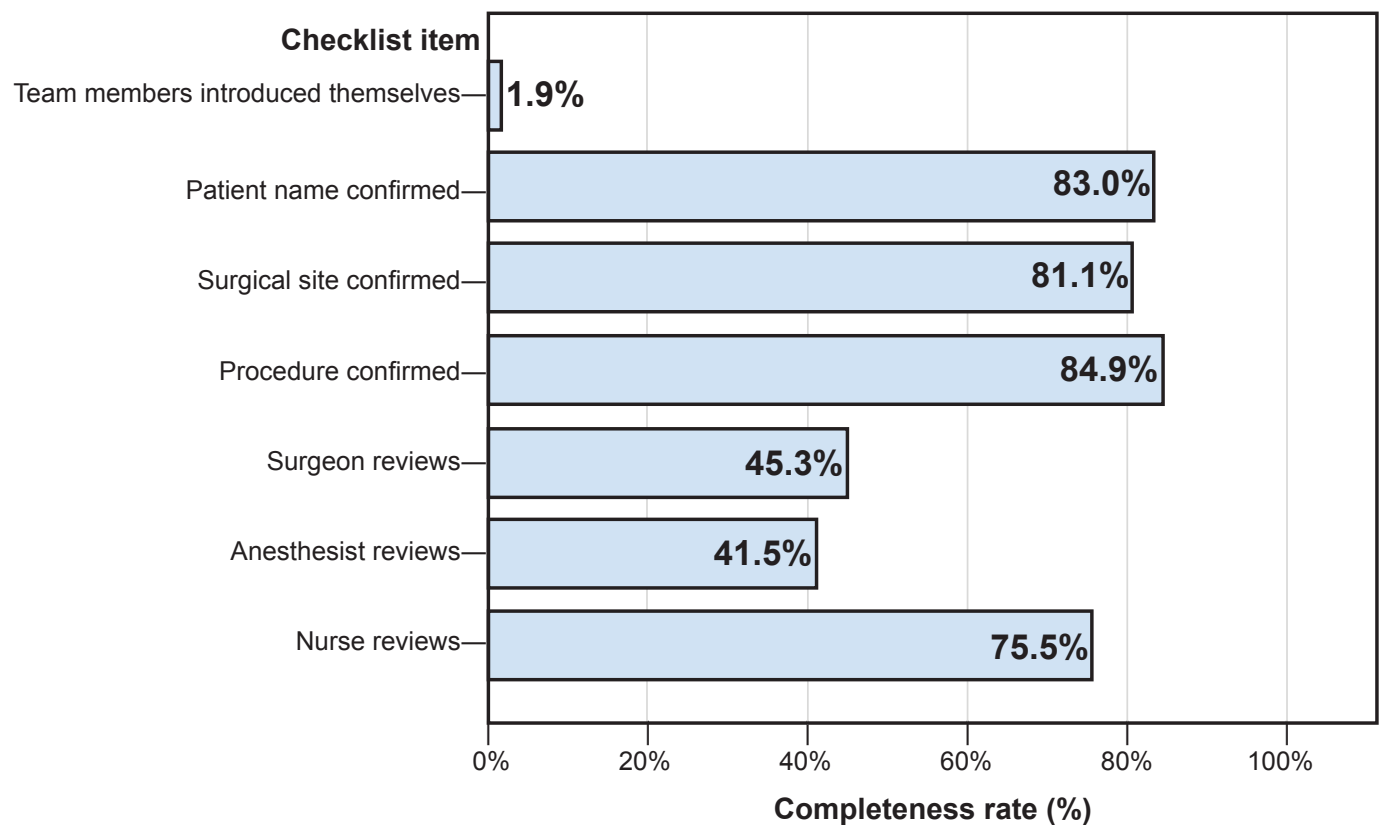

Figure 1. Time-out checklist completeness rates. Bars represent the percentage of procedures for the checked items among the total procedures where time-out was conducted.

patient name, surgical site, and procedure type were confirmed in 44 (83\%), 43 (81.1\%), and 45 (84.9\%) cases, respectively. All concerns and anticipated critical events were completely reviewed in 33\% of time-out cases, with anticipated critical events to surgeons being reviewed in 32 (45.3\%) cases. Concerns from the anesthetist and nursing team were elaborated in 30 (41.5\%) and 49 (75.5\%) cases, respectively (Fig. 1).

Time-out was initiated by circulating nurses in $93 \%$ of observed cases. Over two thirds of the time, time-out was conducted before anesthesia started (see Table 1). All team members were entirely present in about half $(56.7 \%)$ of the time-out cases.

\section{Factors Associated with Time-out Compliance}

Table 2 detailed potential factors associated with the compliance of time-out. The presence of all staff was found to be significantly associated with a higher rate of time-out compliance (17 (89.5\%) out of 19 cases) compared to the cases where time-out was conducted in the presence of only some staff members (13 $(26.5 \%)$ out of 49 cases) $(p<0.001)(O R=0.04 ; 95 \% \mathrm{Cl}$ $=0.01,0.21 ; p<0.001)$, while presence of the primary surgeon was significantly associated with higher rates of compliance compared to their absence (100\% versus 51.5\%; $P<0.001)$. There was no significant association between time-out compliance and the time of the day, as time-out was adhered to almost equally at different times of the day $(p=0.83)$. Our results also reveal that time-out conduction was not significantly associated with the number of procedures performed during the day $(p=0.527)$. It was significantly associated, however, with type of surgery being conducted, in that general surgery, neurosurgery, orthopedic and thoracic teams were shown to be highly adherent to time-out procedures $(74 \%, 60 \%, 64 \%$ and $75 \%$, respectively; $p$ $=0.005)$. There was no statistical significance between the length of time between a patient entering the operating theater to initial skin incision and time-out conduction $(p=0.447)$.

\section{Discussion}

Time-out is a fundamental step in surgical operations as it is vital to maintaining both patient safety and quality of care. Therefore, how well the operating theater team adequately and in a timely manner uses the time-out checklist should be assessed. This study reports the compliance of time-out and how it is being conducted at an academic tertiary care center. A total of 116 elective procedures were evaluated across different surgical specialties. The quality of adopted checklist completion was observed and recorded, as well as factors that might influence the use of time- 
Table 1. Time-out characteristics.

\begin{tabular}{|l|l|c|}
\hline \multicolumn{1}{|c|}{ Characteristics } & Category & N (\%)* \\
\hline \multirow{3}{*}{ Time-out introduced by } & Surgeon & $2(3.77 \%)$ \\
\cline { 2 - 3 } & Nurse & $29(92.45 \%)$ \\
\cline { 2 - 3 } & Anesthetist & $2(3.77 \%)$ \\
\hline \multirow{2}{*}{ Presence of primary surgeon } & Yes & $21(58.82 \%)$ \\
\hline \multirow{3}{*}{ Timing of time-out } & No & $43(81.18 \%)$ \\
\cline { 2 - 3 } & Before anesthesia & $9(16.98)$ \\
\hline \multirow{2}{*}{ White board display } & After intubation & $1(1.89 \%)$ \\
\cline { 2 - 3 } & After incision & $27(50.94 \%)$ \\
\cline { 2 - 3 } & Yes & $26(49.06 \%)$ \\
\hline
\end{tabular}

"Because of missing data, some values do not reach the total number of observations; percentages are calculated according to available data for each variable

Table 2. Factors associated with time-out adherence.

\begin{tabular}{|c|c|c|c|c|c|c|}
\hline \multirow{3}{*}{ Factor } & \multirow{3}{*}{ Category } & \multicolumn{4}{|c|}{ Time-out Implementation } & \multirow{3}{*}{ p-value } \\
\hline & & \multicolumn{2}{|c|}{ Yes } & \multicolumn{2}{|c|}{ No } & \\
\hline & & Freq. & $\%$ & Freq. & $\%$ & \\
\hline \multirow{3}{*}{ Order } & First & 25 & $50.00 \%$ & 25 & $50.00 \%$ & \multirow{3}{*}{0.832} \\
\hline & Middle & 14 & $45.16 \%$ & 17 & $54.84 \%$ & \\
\hline & Last & 9 & $42.86 \%$ & 12 & $57.14 \%$ & \\
\hline Total No. procedures per day & Median, P75 & 2.00 & 5.00 & 3.50 & 5.00 & $0.527^{\mathrm{M}}$ \\
\hline \multirow{12}{*}{ Specialty } & OB/GYN & 5 & $55.55 \%$ & 4 & $44.44 \%$ & \multirow{12}{*}{$0.005^{*}$} \\
\hline & ORL & 7 & $50.00 \%$ & 7 & $50.00 \%$ & \\
\hline & General Surgery & 14 & $73.68 \%$ & 5 & $26.32 \%$ & \\
\hline & Pediatrics & 4 & $28.57 \%$ & 10 & $71.43 \%$ & \\
\hline & Vascular & 0 & $0.00 \%$ & 4 & $100.00 \%$ & \\
\hline & Neurosurgery & 3 & $60.00 \%$ & 2 & $40.00 \%$ & \\
\hline & Orthopedics & 9 & $64.29 \%$ & 5 & $35.71 \%$ & \\
\hline & Thoracic & 3 & $75.00 \%$ & 1 & $25.00 \%$ & \\
\hline & Urology & 1 & $8.33 \%$ & 11 & $91.67 \%$ & \\
\hline & Ophthalmology & 1 & $14.29 \%$ & 6 & $85.71 \%$ & \\
\hline & Hematology \& Special Procedures & 3 & $50.00 \%$ & 3 & $50.00 \%$ & \\
\hline & Cardiothoracic & 0 & $0.00 \%$ & 2 & $100.00 \%$ & \\
\hline \multirow{2}{*}{ Presence of all staff } & Yes & 17 & $89.47 \%$ & 2 & $10.53 \%$ & \multirow{2}{*}{$<0.001^{*}$} \\
\hline & No & 13 & $26.53 \%$ & 36 & $73.47 \%$ & \\
\hline $\begin{array}{l}\text { Time between patient-in- } \\
\text { theatre and incision }\end{array}$ & Min (mean, SD) & 34.55 & 24.28 & 31.29 & 21.29 & 0.447 \\
\hline
\end{tabular}

P75: $75^{\text {th }}$ centile; ${ }^{\text {M: Mann-Whitney U test (nonparametric test) }}$ : Statistically significant result;

OB/GYN: Obstetrics and Gynecology; ORL: Otorhinolaryngology

out checklists and its completion. Identifying such potential factors may improve time-out compliance and prevent further surgical complications.

Although electronic records report 100\% utilization of the time-out checklist in the operating rooms in our setting, a large variation in conducting the time-out was observed. In other words, the actual compliance rate contradicted electronic surgical reports. Of all elective surgeries examined, time-out was properly carried out in only $45.7 \%$ of procedures. This can be explained by the insufficient knowledge of the importance of surgical checklist among operating theater team members, as well as a lack of studies highlighting the negative impact of noncompliance to checklists in the western region of Saudi Arabia. In Toronto, a hospital study showed that the rate of surgical time-out was $99 \%(230 / 232)^{[14]}$. Another study in Switzerland found a $99 \%$ compliance rate of timeout among elective surgeries observed during $2010^{[16]}$.

In this study, time-out was not completely carried out in more than half of the observed cases. Of all examined checklists, names of patients, surgical sites, and procedure names were verbally confirmed in more than $80 \%$. Effective communication between surgical 
team members is essential in time-out practice $^{[17]}$. Therefore, operating team members are expected to introduce their names and roles before any encounter. Our study showed that this key component was overlooked in almost all surgical procedures. This might be a result of a dependency on whiteboard displays that demonstrate the names and roles of each participant and team member, who are usually introduced to one another during their first encounter. This is consistent with a study conducted in Thailand, in which most of the team members failed to introduce their names and roles to each other ${ }^{[18]}$. Patient identification and procedure name were missed in $98 \%$ of our cases. Our study also found that surgical concerns, including those of the surgeons, anesthetists, and nurses, were not discussed in a high number of cases, which could cause serious harm to the patient ${ }^{[19]}$. Team members were not wholly present in $43 \%$ of cases observed and the primary surgeon was absent in $41 \%$ of procedures, which had a significant negative impact on the conduction of time-out. Complete and consistent participation of the surgical team is a crucial element in time-out; otherwise the rate of noncompliance and the risk of unfavorable outcomes increase. Our study found that the presence of all staff is associated with a higher rate of adherence to time-out. In addition, higher rates of compliance were found to be adheredto when the primary surgeon is present. Prior literature showed that lack of leadership is a common cause of noncompliance. Another reason for inadequate timeout conduction is the lack of cooperation among team members during time-out ${ }^{[20]}$. The circulating nurse is the one who usually begins the time-out process, but any member of the operating team can initiate $\mathrm{it}^{\mathrm{t}^{211}}$. In our study, the nurses-initiated time-out in more than $90 \%$ of cases.

All surgeries carry a risk of adverse events occurring. For this reason, it is important to employ time-out equally in all surgical procedures. A difference in adherence to time-out process was noted between surgical specialties, in that general surgery, neurosurgery, orthopedic surgery, and thoracic surgery were found to be better at implementing time-out than other specialties. However, previous studies showed no significant difference in compliance rate among surgical specialties, with the exception of ophthalmology ${ }^{[16]}$.

Our results revealed no significant difference in time-out compliance when observing the interval time between patients entering the operating theater until the initiation of skin incision. This means that time-out implementation caused no significant delay in procedure, may not disrupt the workflow inside the operating theaters, and thus, should be encouraged.

The current study has several unavoidable limitations. First, inter-observer variability was limited in that items checked off on the checklist varied between observers. Second, our results may not be totally generalizable, as data were collected according to a convenient sampling technique. Moreover, our observations were obtained from a single institution, and other elements may arise from other hospitals. Further local studies are also needed to validate or reject our results. Authors were unaware if the surgical teams were oriented. Nevertheless, a sustained educational program should be launched to enhance the adherence to this important phase of surgery and to guarantee consistent quality and accuracy. It is worth mentioning that part of time-out might be conducted in the holding surgical area, where the study team was not present or being involved in the majority of cases.

\section{Conclusion}

At our institution, after 10 years of surgical time-out implementation, compliance rate was suboptimal. This reduction in compliance was improved when all operating theater staff, including the primary surgeon were present before commencing of the operation. For successful time-out implementation and effective communication thereof, the attitudes of operating theater personnel toward time-out should be improved. Therefore, a call for awareness campaigns aimed towards the optimal usage of the safety checklist is suggested. Furthermore, a regular audit on timeout compliance and adherence to the electronic data should be mandated.

\section{Conflicts of Interest}

The author have no conflict of interest.

\section{Disclosure}

The author did not receive any type of commercial support either in forms of compensation or financial for this study. The author has no financial interest in any of the products or devices, or drugs mentioned in this article. 


\section{Ethical Approval}

Obtained.

\section{References}

[1] Weiser TG, Regenbogen SE, Thompson KD, Haynes AB, Lipsitz SR, Berry WR, Gawande AA. An estimation of the global volume of surgery: a modelling strategy based on available data. Lancet 2008; 372(9633): 139-144.

[2] Kable AK, Gibberd RW, Spigelman AD. Adverse events in surgical patients in Australia. Int Soc Qual Heal Care 2002; 14(4): 269-276.

[3] Gawande AA, Thomas EJ, Zinner MJ, Brennan TA. The incidence and nature of surgical adverse events in Colorado and Utah in 1992. Surgery 1999; 126(1): 66-75.

[4] Landais A, Morel M, Goldstein J, Loriau J, Fresnel A, Chevalier C, Rejasse G, Alfonsi P, Ecoffey C. Evaluation of financial burden following complications after major surgery in France: Potential return after perioperative goal-directed therapy. Anaesth Crit Care Pain Med 2017; 36(3): 151-155.

[5] Seiden SC, Barach P. Wrong-side/wrong-site, wrongprocedure, and wrong-patient adverse events: Are they preventable? Arch Surg 2006; 141(9): 931-939.

[6] Hales B, Terblanche M, Fowler R, Sibbald W. Development of medical checklists for improved quality of patient care. Int J Qual Heal Care 2008; 20(1): 22-30.

[7] [No authors listed]. New scientific evidence supports WHO findings: a surgical safety checklist could save hundreds of thousands of lives. World Health Organization 2011.

[8] Haynes AB, Weiser TG, Berry WR, Lipsitz SR, Breizat AH, Dellinger EP, Herbosa T, Joseph S, Kibatala PL, Lapitan MC, Merry AF, Moorthy K, Reznick RK, Taylor B, Gawande AA; Safe Surgery Saves Lives Study Group. A surgical safety checklist to reduce morbidity and mortality in a global population. N Engl J Med 2009; 360 (5): 491-499.

[9] World Health Organization \& WHO Patient Safety. Implementation manual: WHO surgical safety checklist (first edition). World Health Organization. 2008. <https://apps.who.int/iris/handle/10665/70046>.

[10] Lee S. The extended surgical time-out: does it improve quality and prevent wrong-site surgery? Perm J 2010; 14(1): 19-23

[11] Böhmer AB, Wappler F, Tinschmann T, Kindermann P, Rixen D, Bellendir M, Schwanke U, Bouillon B, Gerbershagen MU. The implementation of a perioperative checklist increases patients perioperative safety and staff satisfaction. Acta Anaesthesiol Scand 2012; 56(3): 332-338.

[12] Papaconstantinou HT, Jo C, Reznik SI, Smythe WR, WehbeJanek $\mathrm{H}$. Implementation of a surgical safety checklist: impact on surgical team perspectives. Ochsner J 2013; 13(3): 299-309.

[13] Johnston G, Ekert L, Pally E. Surgical site signing and "time out": issues of compliance or complacence. J Bone Jt Surg - Ser A 2009; 91(11): 2577-2580.
[14] Khoshbin A, Lingard L, Wright JG. Evaluation of preoperative and perioperative operating room briefings at the Hospital for Sick Children. Can J Surg 2009; 52(4): 309-315.

[15] Vats A, Vincent CA, Nagpal K, Davies RW, Darzi A, Moorthy K. Practical challenges of introducing WHO surgical checklist: UK pilot experience. BMJ 2010; 340: b5433.

[16] Cullati S, Le Du S, Rae AC, Micallef M, Khabiri E, Ourahmoune A, Boireaux A, Licker M, Chopard P. Is the Surgical Safety Checklist successfully conducted? An observational study of social interactions in the operating rooms of a tertiary hospital. BMJ Qual Saf 2013; 22(8): 639-646.

[17] Lingard L, Espin S, Rubin B, Whyte S, Colmenares M, Baker GR, Doran D, Grober E, B Orser B, Bohnen J, Reznick R. Getting teams to talk: development and pilot implementation of a checklist to promote interprofessional communication in the OR. Qual Saf Health Care 2005; 14(5): 340-346.

[18] Lingard L, Espin S, Whyte S, Regehr G, Baker GR, Reznick R, Bohnen J, Orser B, Doran D, Grober E. Communication failures in the operating room: an observational classification of recurrent types and effects. Qual Saf Health Care 2004; 13(5): 330-334.

[19] Kasatpibal N, Senaratana W, Chitreecheur J, Chotirosniramit N, Pakvipas P, Junthasopeepun P. Implementation of the World Health Organization surgical safety checklist at a university hospital in Thailand. Surg Infect (Larchmt) 2012; 13(1): 50-56.

[20] Melekie TB, Getahun GM. Compliance with Surgical Safety Checklist completion in the operating room of University of Gondar Hospital, Northwest Ethiopia. BMC Res Notes 2015; 8: 361.

[21] Dillon KA. Time out: an analysis. AORN J 2008; 88(3): 437442. 
An Audit on Compliance of Surgical Time-Out after a Decade of Implementation at an Academic Tertiary Care Hospital T. A. Al-Khatib et al.

Appendix 1

\begin{tabular}{|l|l|}
\hline \multicolumn{2}{|c|}{ Surgical Specialties Screened for Time-Out Compliance } \\
\hline - General Surgery & - Otorhinolaryngology Surgery \\
- Cardiac Surgery & - Ophthalmic Surgery \\
- Neurosurgery & - Obstetrics and Gynecology Surgery \\
- Plastic Surgery & - Emergent Surgery \\
- Urology Surgery & - Pediatric Surgery \\
- Orthopedics Surgery & - Hematology, Endoscopy \& Other Special Procedures \\
\hline
\end{tabular}

Appendix 2

Elements of Surgical Time-0ut

- Confirm all team members have introduced themselves and their roles.

- Confirm patient name, procedure site and procedure name.

- Surgeons reviews: (critical or unexpected steps, operative duration and anticipated blood loss)

- $\quad$ Anesthesia team reviews: (any patients-specific concerns)

- $\quad$ Nursing team reviews: (sterility confirmed, any equipment issues and any concerns) 


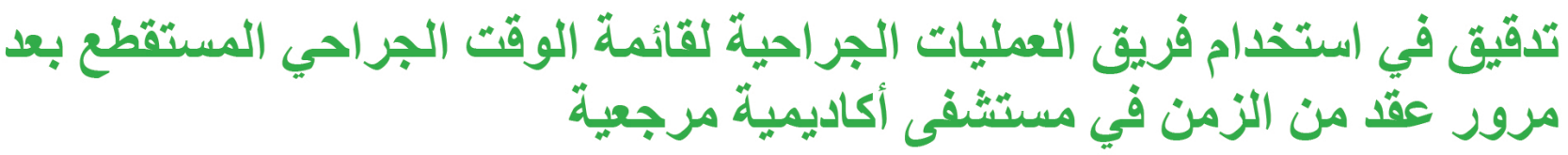

طلال أحمد الخطيب' و أحمد عبدالروعوف مرزا' و منار عبدالناصر ملاكه' و افنان عصام جفري' و

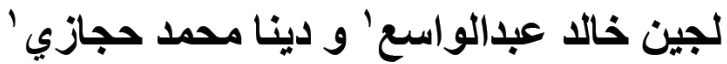

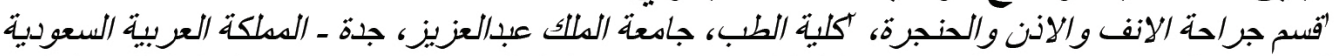
"قسم جراحة الانف والانن والدنجرة، كلية الطب برابغ، جامعة الملك عبدالعزيز، جدة ـ الدملكة العربية السعودية،

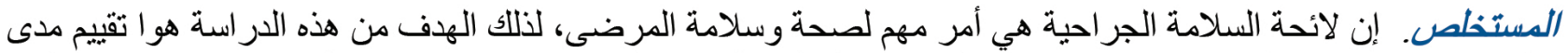

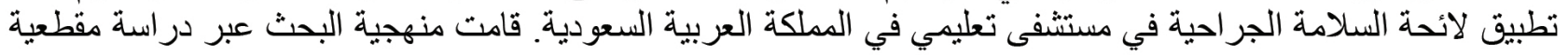

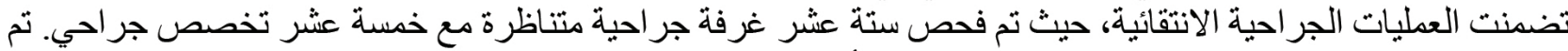

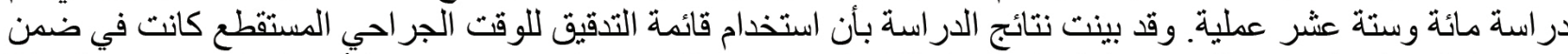

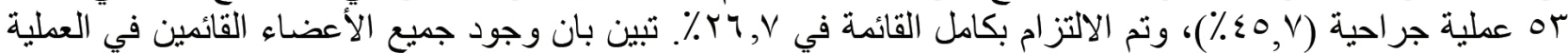

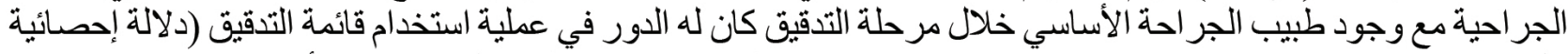

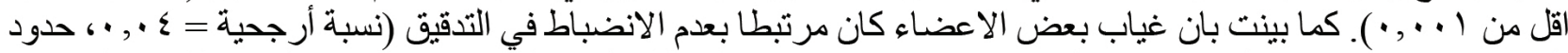

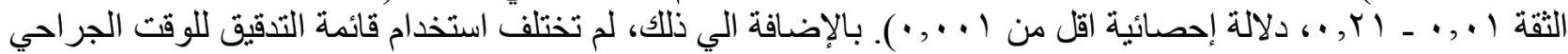

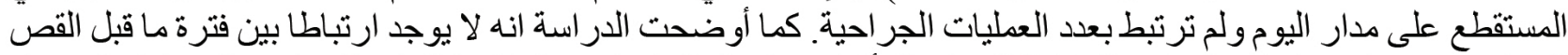

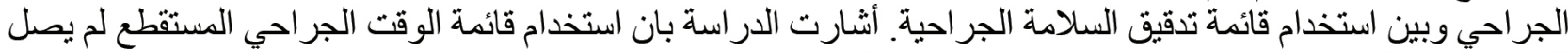

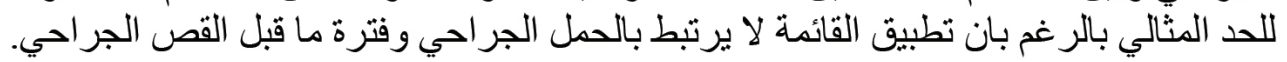

